\title{
Association between crack cocaine use and reduced salivary flow
}

\section{Raquel Pippi ANTONIAZZI (a) Amanda Rodrigues SARI (b) Maísa CASARIN(c) Cristina Machado Bragança de MORAES(a) Carlos Alberto FELDENS(d)}

(a) Centro Universitário Franciscano, Santa Maria, RS, Brazil;

(b) Universidade Federal do Rio Grande do Sul - UFRGS, Faculty of Dentistry, Porto Alegre, Brazil.

(c) Universidade Federal de Santa Maria - UFSM, Faculty of Dentistry, Santa Maria, RS, Brazil.

(d) Universidade Luterana do Brasil, Postgraduate program in Dentistry, Canoas, RS, Brazil.
Declaration of Interest: The authors certify that they have no commercial or associative interest that represents a conflict of interest in connection with the manuscript.

\section{Corresponding Author:}

Raquel Pippi Antoniazzi

E-mail: raquelantoniazzi@hotmail.com

htps://doi.org/10.1590/1807-3107BOR-2017.vol31.0042

Submitted: Aug 05, 2015

Accepted for publication: Mar 23, 2017

Last revision: Apr 17, 2017

\begin{abstract}
Crack cocaine use appears to have an impact on oral conditions. However, changes in the salivary flow among crack users have not been fully clarified. The aim of this study was to compare stimulated salivary flow and the occurrence of hyposalivation between crack users and non-users. A cross-sectional study was conducted involving 40 crack users and 40 controls matched for sex, age, and smoking habits. Interviews were conducted to acquire data on the perception of dry mouth (xerostomia) and drug use. Stimulated salivary flow was determined using the spitting method. A significant reduction in stimulated salivary flow was found among crack users in comparison to non-users (1.02 vs. $1.59 \mathrm{ml} / \mathrm{min})$. A total of $42.5 \%$ and $15 \%$ of crack users had very low and low stimulated salivary flow, respectively. Moreover, $65 \%$ of users reported xerostomia in comparison to $37.5 \%$ non-users $(p<0.012)$. No significant association was found between xerostomia and hyposalivation $(\mathrm{p}=0.384)$. A multivariate analysis revealed that individuals older than 26 years of age, those with a low household income, and crack users (prevalence ratio: 2.59) had a significant association with the occurrence of hyposalivation. A significant association was found between the use of crack and reduced salivary flow. The use of crack was associated with the occurrence of hyposalivation in the multivariate analysis.
\end{abstract}

Keywords: Crack Cocaine; Drug Users; Saliva; Xerostomia.

\section{Introduction}

Crack cocaine use is characterized as a public health problem mainly due to the systemic ${ }^{1,2}$ and behavioral consequences. ${ }^{3}$ In the oral cavity, crack appears to generate heat, vasoconstriction, harmful effects to the immune response, and higher prevalence of periodontitis. ${ }^{4,5,6,7}$ However, the occurrence of changes in salivary flow among crack users has not been fully clarified.

Saliva has different functions in the oral cavity, such as physical-mechanical cleaning, tissue protection, lubrication, hydration, permeability barrier formation, changes in microbiota, the regulation of the calcium/phosphate balance, antacid action, the digestion of the food bolus, and swallowing. ${ }^{8}$ Salivary flow is essential for these actions ${ }^{9}$ and a reduction in salivary flow can lead to an increase in the occurrence of dental caries, oral infections, gastrointestinal complications, and a reduction in the quality of life..$^{10,11}$ 
Hyposalivation is defined as an objective measure of a reduction in salivary flow and is associated with xerostomia, which is the subjective perception of dry mouth. ${ }^{12}$ Hyposalivation can be caused by different factors, such as systemic diseases, the use of medications, radiotherapy of the head and neck, ${ }^{12}$ and the use of illicit drugs. ${ }^{13,14}$

Cannabis, ecstasy, and methamphetamine are illicit drugs already associated with dry mouth. ${ }^{13,14,15}$ Despite the sympathomimetic effects of cocaine, there is little evidence of dry mouth found in the drug dependents. ${ }^{16}$ A study of crack users showed a reduced $\mathrm{pH}$ and normal salivary flow compared to non-users. ${ }^{17}$

The effect of crack in salivary flow is poorly known. This information is important for planning prevention strategies as well as improving healthcare and recovery of dependent individuals. Thus, the aim of the present study was to compare stimulated salivary flow between crack users and non-users.

\section{Methodology}

\section{Participants and study design}

A cross-sectional study with a control group was conducted in the city of Santa Maria, state of Rio Grande do Sul, Brazil, in two facilities for the treatment of chemical dependency. The data were collected between August 2012 and December 2013. This study received approval from the human research ethics committee of the Franciscan University Center (Brazil) under process number 02451812.6.0000.5306. All participants signed a statement of informed consent.

Eligible individuals exposed to crack were in treatment for chemical dependency, used the drug for at least 1 year, and were free of neurological or psychological disorders. Further details on the methods used in this study can be found in a previous publication. ${ }^{7}$ Each crack user was paired with a control who had never used any street drugs and was matched for sex, age ( \pm 3 years), and exposure to tobacco (smoker or never smoked). This group was recruited from public schools and screening (previously submitted for dental examination) at the dentistry course of the Franciscan University Center in Santa Maria, state of Rio Grande do Sul, Brazil.
The sample was calculated based on the difference in mean and standard deviation of salivary $\mathrm{pH}$ between crack users and controls (7.11 \pm 0.21 and $7.26 \pm 0.25$, respectively), ${ }^{17}$ at a $5 \%$ significance level and $95 \%$ confidence interval. Considering a proportion of 1:1, a minimum of 38 participants was needed for each group.

\section{Data collection}

A face-to-face questionnaire was administered on the use of drugs (crack, cocaine, heroin, marijuana, alcohol, tobacco, and others). This questionnaire has been tested and adapted for use on the Brazilian population..$^{18}$ Demographic, socioeconomic, medical, and dental data were also collected.

\section{Exposure and adjustment variables}

The variables were categorized into the following: age in years [ $\leq$ or $>26$ years (median of controls)]; sex (female or male); self-reported skin color (white or non-white); schooling in completed years of study; household income based on the Brazilian monthly minimum salary [BMMS $=\mathrm{R} \$ 750$, approximately equivalent to US\$ 300 during the study (median of controls: $\leq 1 />1$ BMMS)]; tobacco use [non-smoker ( $\leq$ 1 pack in lifetime) and smoker (current smoker)]; crack cocaine use [(never used/used for at least one year) or (adapted $\left.{ }^{18}\right)$ ]; xerostomia [does your mouth feel dry? (no or yes) $)^{19}$; the use of medications that can reduce salivary flow [diuretics, laxatives, antacid, anorectic, antihypertensive, antidepressant, antipsychotic, sedative, antihistamine, anticholinergic, Parkinson's medication (yes or no)]; decayed, missing, filled teeth (DMFT) index $\left[(\text { median of controls: } \leq 5 />5)^{20}\right]$; missing teeth (median of controls: $\leq 2$ or $>2$ ); periodontal disease [defined as at least three sites with clinical attachment level (CAL) $>4 \mathrm{~mm}$ and at least two sites with probing depth $(\mathrm{PD})>3 \mathrm{~mm}$. However, these conditions did not have to be present at the same site or tooth. ${ }^{21}$ All erupted teeth (except third molars) were evaluated. The clinical examinations were performed by a single examiner who had undergone training and calibration exercises. The PD, CAL, and DMFT measures were determined on 22 individuals and repeated after a 2 -h period. The Kappa coefficients ranged from 0.83 to 0.96 prior to and 7 months after the onset of the study. 


\section{Stimulated salivary flow}

The amount of saliva was determined by the chewing of a mechanical stimulus $(2 \times 2 \mathrm{~cm}$ strip of rubber). The participants were instructed not to eat, drink (except water), or smoke $1 \mathrm{~h}$ prior to the saliva collection. Salivary flow was determined using the spitting collection method ${ }^{22}$ between 8:30 am and $12 \mathrm{pm}$. The participant was seated in a comfortable chair and instructed not to speak or interrupt the collection process. Otherwise, the collection would be initiated again. Chewing was performed with a sterile strip of rubber of a standardized size and the collection duration lasted for $5 \mathrm{~min}$. Prior to the collection, the participants were instructed to maintain a regular and calm chewing pace. The collection of saliva after the first 2 min was discarded to avoid the possible presence of food scraps that could influence the weight of the saliva. After every $60 \mathrm{~s}$, the patients expelled the saliva into a previously defined and weighed recipient. The researcher timed the collection with a chronometer. The amount of saliva was determined based on weight, which was measured using a precision scale (Balança Eletrônica, Gehaka BG 200). Saliva was expressed as $\mathrm{ml} / \mathrm{min}$, which is similar to $\mathrm{g} / \mathrm{min}$ and was used to determine the velocity of salivary secretion. Salivary flow was determined by a trained examiner. Stimulated salivary flow was categorized as normal (> $1 \mathrm{ml} / \mathrm{min})$, low $(0.7-1.0 \mathrm{ml} / \mathrm{min})$ or very low $(<0.7 \mathrm{ml} / \mathrm{min}){ }^{23,24}$ Hyposalivation was considered when a participant had low salivary flow $(\leq 1 \mathrm{ml} / \mathrm{min})$.

\section{Data analysis}

The data were expressed as mean, standard deviation, and median values. The Shapiro-Wilk test was used to determine the distribution (normal or non-normal) of the data. Simulated salivary flow, hyposalivation, and xerostomia were compared between crack users and non-users using the Wilcoxon and McNemar tests, with a $5 \%$ level of significance. Poisson regression models with robust variables were run to evaluate co-variables (age, sex, skin color, crack use, smoking, alcohol use, xerostomia, missing teeth, and the DMFT index) associated with hyposalivation. Variables with a high $\mathrm{p}$-value were removed from the model one by one until only those with a p-value $<0.20$ remained. The data were analyzed with the aid of the Statistical Package for theSocial Sciences (SPSS, version 22.0, Chicago, IL, USA).

\section{Results}

In total, 74 crack users were eligible for the study. Of these, 21 were excluded for being pregnant, HIV positive and/or having used crack for less than 1 year, 8 were considered unable to answer the questions during the interview, 3 refused to participate, and 2 were not present during the three attempts to obtain the collections. The total sample was composed of 83 individuals. Additionally, 2 crack users and 1 non-user were excluded due to problems during the collection, transportation, and weighing of the saliva samples.

Thus, the data from 80 individuals (40 in each group) were analyzed. Both groups were predominantly male $(80 \%), 85 \%$ were smokers and $15 \%$ were non-smokers, and age ranged from 14 to 46 years (Table 1). Exposed individuals used crack for $4.6 \pm 3.72$ years, with a mean of $20.72 \pm 26.28$ rocks per day. Mean duration in the rehabilitation facility was $79.90 \pm 84.64$ days, but $35 \%$ had been interned for less than 21 days. A majority of crack users had previously or concomitantly taken other street drugs, such as marijuana (75\%), cocaine $(87.5 \%)$, and inhalants (37.5\%).

Table 1. Distribution of demographic variables of participants $(\mathrm{n}=40)$.

\begin{tabular}{lcc}
\hline \multirow{2}{*}{\begin{tabular}{l} 
Variable \\
\cline { 2 - 3 } Matched characteristics
\end{tabular}} & $\mathrm{n}(\%)$ & $\mathrm{n}(\%)$ \\
\hline Age (Years) & & \\
$\quad$ Mean \pm SD & $27.32 \pm 7.27$ & $26.43 \pm 6.99$ \\
Sex & & \\
Female & $8(20)$ & $8(20)$ \\
Male & $32(80)$ & $32(80)$ \\
Tobacco use & & $6(15)$ \\
Non-smoker & $6(15)$ & $34(85)$ \\
Smoker & $34(85)$ & \\
Unmatched characteristics & & \\
Ethnicity & & $28(70)$ \\
White & $31(77.50)$ & $12(30)$ \\
Non-white & $9(22.50)$ & $8.54 \pm 2.70$ \\
Schooling (years) & & $1370.71 \pm 906.85$ \\
\hline Mean \pm SD & $9.81 \pm 2.13$ & \\
Household income & & \\
Mean \pm SD & $1548.65 \pm 729.77$ & \\
\hline
\end{tabular}


Crack users exhibited a significant reduction in stimulated salivary flow compared to non-users ( $1.02 \mathrm{vs} .1 .59 \mathrm{ml} / \mathrm{min}$, respectively) $(\mathrm{p}<0.001)$. A total of $42.5 \%$ and $15 \%$ of crack users had very low and low stimulated salivary flow, respectively ( $p<0.001)$. Moreover, $65 \%$ of crack users perceived dry mouth in comparison to $37.5 \%$ on non-users $(\mathrm{p}<0.012)$ (Table 2$)$. However, no significant association was found between xerostomia and hyposalivation $(\mathrm{p}=0.384)$ (Figure 1$)$.

The crude model revealed that the prevalence of hyposalivation was 2.88 -fold greater among crack users. After adjustment for possible confounding variables, the prevalence of hyposalivation was 2.59-fold greater among crack users (prevalence ratio, 2.59 and 95\% confidence interval, 1.37-4.90). Moreover, the multivariate analysis demonstrated that the prevalence of the outcome was also significantly higher among individuals older than 26 years and those with a household income less than the BMMS (Table 3).

\section{Discussion}

In the present study, salivary flow was compared between crack users and non-users and a significant reduction in stimulated salivary flow along with a greater occurrence of hyposalivation was found among the crack users.

The occurrence of xerostomia in users of illicit drugs has been reported in previous studies, which is in agreement with the present findings. ${ }^{13,1,1,15,25}$ However, only one study compared the salivary characteristics between crack users and controls that detected the changes in salivary $\mathrm{pH}$ but not in salivary flow or buffering capacity ( $p>0.05) \cdot{ }^{17}$ Likewise, nearly all crack users took other legal and street drugs prior or concomitantly to crack, such as marijuana, cocaine, and tobacco, and alcohol. The control group was composed nearly completely of smokers. These factors may have contributed to the reduction in salivary flow in both groups. ${ }^{14}$

A reduction in normal salivary flow may or may not be accompanied by xerostomia, which is characterized by a subjective sensation of dry mouth. ${ }^{19,26}$ In the present study, xerostomia was not significantly associated with a reduction in salivary
Table 2. Comparison of stimulated salivary flow and xerostomia between crack users and non-users $(n=40)$.

\begin{tabular}{|c|c|c|c|}
\hline Variable & Crack users & Crack non-users & $\mathrm{p}$ \\
\hline \multicolumn{2}{|c|}{ Stimulated salivar flow (ml/min) } & & $<0.001^{*}$ \\
\hline Mean \pm SD & $1.02 \pm 0.70$ & $1.59 \pm 0.64$ & \\
\hline $\begin{array}{l}\text { Median } \\
\text { (P25-P75) }\end{array}$ & $0.87(0.46-1.52)$ & $1.34(1.07-2.10)$ & \\
\hline Salivar flow & & & $<0.001^{* *}$ \\
\hline $\begin{array}{l}\text { Normal } \\
(>1 \mathrm{ml} / \mathrm{min})\end{array}$ & $17(42.5)$ & $32(80.0)$ & \\
\hline $\begin{array}{l}\text { Low } \\
(0.7-1 \mathrm{ml} / \mathrm{min})\end{array}$ & $6(15.0)$ & $7(17.5)$ & \\
\hline $\begin{array}{l}\text { Very low } \\
(<0.7 \mathrm{ml} / \mathrm{min})\end{array}$ & $17(42.5)$ & $1(2.5)$ & \\
\hline Xerostomia & & & $0.012^{* *}$ \\
\hline No & $14(35.0)$ & $25(62.5)$ & \\
\hline Yes & $26(65.0)$ & $15(37.5)$ & \\
\hline
\end{tabular}

*Wilcoxon test; ${ }^{* *} \mathrm{McNemar}$ test.

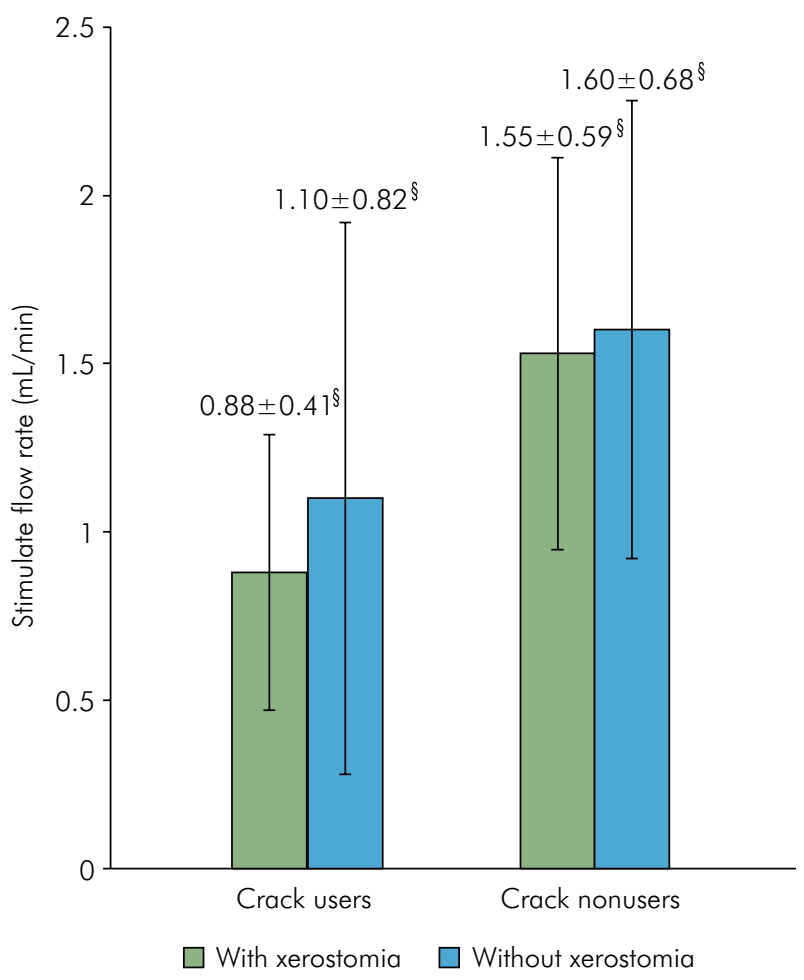

Figure 1. Association between xerostomia and stimulated salivary flow in crack users and non-users ( $\S$ Mean \pm standard deviation). 
Table 3. Association between hyposalivation and demographic, behavioral, and clinical variables.

\begin{tabular}{|c|c|c|c|c|c|c|}
\hline Variable & $\mathrm{n}$ & Hyposalivation n (\%) & $\mathrm{RP}^{*}(95 \% \mathrm{Cl})$ crude & $\mathrm{p}$ & $\mathrm{RP}^{*}(95 \% \mathrm{Cl})$ Adjusted & $p$ \\
\hline \multicolumn{7}{|l|}{ Age (years) } \\
\hline$\leq 26$ & 41 & $10(24.4)$ & 1.0 & 0.011 & 1.0 & 0.001 \\
\hline$>26$ & 39 & $21(53.8)$ & $2.21(1.20-4.07)$ & & $2.52(1.50-4.24)$ & \\
\hline \multicolumn{7}{|c|}{ Household income ${ }^{\#}$} \\
\hline$\leq 1 \mathrm{BMW}$ & 38 & $20(52.6)$ & 1.0 & 0.015 & 1.0 & 0.024 \\
\hline$>1 \mathrm{BMW}$ & 42 & $11(26.2)$ & $0.45(0.24-0.86)$ & & $0.52(0.29-0.92)$ & \\
\hline \multicolumn{7}{|l|}{ Crack users } \\
\hline No & 40 & $8(20.0)$ & 1.0 & 0.002 & 1.0 & 0.003 \\
\hline Yes & 40 & $23(57.5)$ & $2.88(1.46-5.65)$ & & $2.59(1.37-4.90)$ & \\
\hline \multicolumn{7}{|l|}{ Missing teeth } \\
\hline$\leq 2$ teeth & 65 & $23(35.4)$ & 1.0 & 0.163 & - & - \\
\hline$>2$ teeth & 15 & $8(53.3)$ & $1.51(0.85-2.68)$ & & & - \\
\hline \multicolumn{7}{|l|}{ Periodontitis } \\
\hline No & 52 & $15(28.8)$ & 1.0 & 0.012 & - & - \\
\hline Yes & 28 & $16(57.1)$ & 1.98 (1.16-3.38) & & - & - \\
\hline \multicolumn{7}{|l|}{ DMFT } \\
\hline$\leq 5$ & 39 & $9(23.1)$ & 1.0 & 0.010 & - & - \\
\hline$>5$ & 41 & $22(53.7)$ & $2.33(1.23-4.41)$ & & - & - \\
\hline
\end{tabular}

flow (hyposalivation), which is in agreement with data described in the literature. ${ }^{9}$

Different factors are associated with the reduction in salivary flow, such as smoking, alcohol, the use of street drugs, beverages with caffeine, and systemic diseases (especially Sjögren's syndrome). ${ }^{14,27}$ However, reduced salivary flow is more commonly associated with the use of medications, such as diuretics, laxatives, antacids, anorectics, anti-hypertension agents, antidepressants, antipsychotics, sedatives, antihistamines, anticholinergics, and medications for the treatment of Parkinson's Disease. ${ }^{14,28,29}$ Individuals who take two or more medications have a 5.5-fold greater chance of having low salivary flow $(<0.7 \mathrm{ml} / \mathrm{min}$ ) in comparison to individuals who take no medication..$^{19}$ Among the crack users in the present study, $52.5 \%$ were taking some type of medication at the time of saliva collection, such as anxiolytics, anticonvulsants, antihistamines, antipsychotics, and antidepressants. However, no association was found between the use of medication and hyposalivation. This may be explained by the fact that $73.4 \%$ of crack users were taking medications only at the beginning of the treatment period (detoxification period in a maximum of 21 days).

In the adjusted model, an age over 26 years, income, and crack use remained associated with hyposalivation. A meta-analysis showed that the aging process is associated with reduced salivary flow. ${ }^{30}$ Drug use may be associated with systemic and local factors. With regard to systemic factors, some drugs may increase sympathetic activity in the central nervous system, reducing salivary secretion through the stimulation of alpha receptors. ${ }^{25}$ Considering local factors, drug use seems to generate vasoconstriction, ${ }^{4,5}$ which is similar to what occurs among smokers and is also associated with a reduction in salivary control. ${ }^{31}$

The gold standard for determining the limit between normal and abnormal salivary flow is not yet clear in the literature. However, normal salivary flow is considered to be between 0.7 and $1.5 \mathrm{ml} / \mathrm{min} .{ }^{32}$ Some authors consider hyposalivation to be at a stimulated salivary flow with a rate lower than $0.7 \mathrm{ml} / \mathrm{min},{ }^{24}$ whereas others consider $0.5 \mathrm{ml} / \mathrm{min}$ to be the cutoff point. ${ }^{33}$ 
Ericsson and Hardwick ${ }^{23}$ propose three categories for mean stimulated salivary flow: $>0.7 \mathrm{ml} / \mathrm{min}$, very low; $0.7-1.0 \mathrm{ml} / \mathrm{min}$, low; and $1 \mathrm{ml} / \mathrm{min}$, normal. However, such limits are not well established. In the present investigation, hyposalivation was defined as below $\leq 1 \mathrm{ml} / \mathrm{min}$ due to the small prevalence of very low stimulated salivary flow $(<0.7 \mathrm{ml} / \mathrm{min})$ in the control group. Moreover, our interest was to evaluate factors that can exert an impact on salivary flow rather than the impact of hyposalivation on oral conditions. Most studies addressing reduced salivary flow use the spitting collection method established by Navazesh ${ }^{34}$. Objective measures of saliva quantity and quality are obtained through salivary stimulation ${ }^{22}$ and different methods are used to stimulate salivary secretion, including the chewing of gum, paraffin wax, rubber strips, and citric acid..$^{35}$

There is evidence that a very low salivary flow significantly increases the risk of developing dental caries $^{36}$, which underscores the importance of the recognition of reduced salivary flow by dentists. Because a permanent manner for increasing saliva is not yet known, ${ }^{37}$ preventive measures regarding dental caries should be performed.

The present study has limitations that should be addressed. The two study groups were composed of convenience samples; therefore, the findings do not represent the general population. Moreover, reference

\section{References}

1. Ribeiro M, Dunn J, Laranjeira R, Sesso R. High mortality among young crack cocaine users in Brazil: a 5-year follow-up study. Addiction. 2004;99(9):1133-5. https://doi.org/10.1111/j.1360-0443.2004.00804.x

2. Morano JP, Gibson BA, Altice FL. The burgeoning HIV/HCV syndemic in the urban Northeast: HCV, HIV, and HIV/HCV coinfection in an urban setting. PLoS One. 2013; 14;8(5):e64321. https://doi.org/10.1371/journal.pone.0064321

3. Narvaez JC, Jansen K, Pinheiro RT, Kapczinski F, Silva RA, Pechansky $F$ et al. Psychiatric and substance-use comorbidities associated with lifetime crack cocaine use in young adults in the general population. Compr Psychiatry. 2014;55(6):1369-76. https://doi.org/10.1016/i.comppsych.2014.04.021

4. Mitchell-Lewis DA, Phelan JA, Kelly RB, Bradley JJ, Lamster IB. Identifying oral lesions associated with crack cocaine use. J Am Dent Assoc. 1994;125(8):1104-8. https://doi.org/10.14219/jada.archive.1994.0122 centers may concentrate individuals with a greater occurrence and severity of the disease, which could exert an influence on the differences detected between the groups. The two groups were matched for variables that could confound the outcome (sex, age, and tobacco use), and most of the controls were recruited from public schools, thereby exhibiting a similar socioeconomic status to that of the crack users, and did not seek any reference treatment center. The cross-sectional design does not allow the establishment of a relationship of causality. Another limitation was the fact that no investigation was made regarding saliva quality, such as $\mathrm{pH}$ and buffering capacity.

\section{Conclusion}

Crack users have a significant reduction in salivary flow and a greater occurrence of hyposalivation in comparison to non-users, independent of socio-demographic, behavioral, or clinical factors.

\section{Acknowledgments}

The authors are grateful to the volunteers who participated in this study. This study was supported by the State of Rio Grande do Sul Research Foundation (FAPERGS-12/1655-7), Brazil. The authors declare no conflicts of interest.
5. Baldwin GC, Buckley DM, Roth MD, Kleerup EC, Tashkin DP. Acute activation of circulating polymorphonuclear neutrophils following in vivo administration of cocaine: a potential etiology for pulmonary injury. Chest. 1997;111(3):698-705. https://doi.org/10.1378/chest.111.3.698

6. Woyceichoski IE, Arruda EP, Resende LG, Machado MA, Grégio AM, Azevedo LR et al. Cytomorphometric analysis of crack cocaine effects on the oral mucosa. Oral Surg Oral Med Oral Pathol Oral Radiol Endod. 2008;105(6):745-9. https://doi.org/10.1016/j.tripleo.2007.09.011

7. Antoniazzi RP, Zanatta FB, Rösing CK, Feldens CA. Association among periodontitis and the use of crack cocaine and other illicit drugs. J Periodontol. 2016;87(12):1396-405. https://doi.org/10.1902/jop.2016.150732

8. Mandel ID. The role of saliva in maintaining oral homeostasis. J Am Dent Assoc. 1989;119(2):298-304. https://doi.org/10.14219/jada.archive.1989.0211 
9. Ship JA, Fox PC, Baum BJ. How much saliva is enough? "Normal" function defined. J Am Dent Assoc.1991;122(3):63-9. https://doi.org/10.14219/jada.archive.1991.0098

10. Pedersen AM, Bardow A, Jensen SB, Nauntofte B. Saliva and gastrointestinal functions of taste, mastication, swallowing and digestion. Oral Dis. 2002;8(3):117-29. https://doi.org/10.1034/j.1601-0825.2002.02851.x

11. Thomson WM, Lawrence HP, Broadbent JM, Poulton R. The impact of xerostomia on oral-health-related quality of life among younger adults. Health Qual Life Outcomes. 2006;8;4:86. https://doi.org/10.1186/1477-7525-4-86

12. Orellana MF, Lagravère MO, Boychuk DG, Major PW, Flores-Mir C, Ortho C. Prevalence of xerostomia in population-based samples: a systematic review. J Public Health Dent. 2006;66(2):152-8. https://doi.org/10.1111/j.1752-7325.2006.tb02572.x

13. Duxbury AJ. Ecstasy: dental implications. Br Dental J. 1993;175(1):38. https://doi.org/10.1038/sj.bdj.4808200

14. Scully C. Drug effects on salivary glands: dry mouth. Oral Dis. 2003;9(4):165-76. https://doi.org/10.1034/j.1601-0825.2003.03967.x

15. Rommel N, Rohleder NH, Wagenpfeil S, Haertel-Petri R, Kesting MR. Evaluation of methamphetamine-associated socioeconomic status and addictive behaviors, and their impact on oral health. Addict Behav. 2015;50:182-7. https://doi.org/10.1016/j.addbeh.2015.06.040

16. Parry J, Porter S, Scully C, Flint S, Parry MG. Mucosal lesions due to oral cocaine use. Br Dent J. 1996;22;180(12):462-4.

17. Woyceichoski IE, Costa CH, Araújo CM, Brancher JA, Resende LG, Vieira I et al. Salivary buffer capacity, $\mathrm{pH}$, and stimulated flow rate of crack cocaine users.

J Investig Clin Dent. 2013;4(3):160-3. https://doi.org/10.1111/j.2041-1626.2012.00126.x

18. Smart RG, Hughes DPH, Johnston LD, Anumonye A, Khant U, Medina-Mora ME. Methodology for students drug-use surveys. Geneva: World Health Organization; 1980.

19. Flink H, Bergdahl M, Tegelberg A, Rosenblad A, Lagerlöf $F$. Prevalence of hyposalivation in relation to general health, body mass index and remaining teeth in different age groups of adults. Community Dent Oral Epidemiol. 2008;36(6):523-31. https://doi.org/10.1111/i.1600-0528.2008.00432.x

20. World Health Organization. Oral health surveys: basic methods. Geneva: World Health Organization; 1997.

21. Borrell LN, Burt BA, Taylor GW. Prevalence and trends in periodontitis in the USA: the [corrected] NHANES, 1988 to 2000. J Dent Res. 2005;84(10):924-30. https://doi.org/10.1177/154405910508401010

22. Navazesh M, Christensen CM. A comparison of whole mouth resting and stimulated salivary measurement procedures. J Dent Res. 1982; 61(10):1158-62. https://doi.org/10.1177/00220345820610100901
23. Ericsson Y, Hardwick L. Individual diagnosis, prognosis and counselling for caries prevention. Caries Res. 1978;12 Suppl 1:94-102. https://doi.org/10.1159/000260369

24. Nederfors T. Xerostomia and hyposalivation. Adv Dent Res. 2000;14(1):48-56. https://doi.org/10.1177/08959374000140010701

25. Curtis EK. Meth mouth: a review of methamphetamine abuse and its oral manifestations. Gen Dent. 2006;54(2):125-9.

26. Wang SL, Zou ZJ, Wu QG, Sun KH. Sialographic changes related to clinical and pathologic findings in chronic obstructive parotitis. Int J Oral Maxillofac Surg. 1992;21(6):364-8. https://doi.org/10.1016/S0901-5027(05)80764-7

27. Antoniazzi RP, Miranda LA, Zanatta FB, Islabão AG, Gustafsson A, Chiapinotto GA et al. Periodontal conditions of individuals with Siögren's syndrome. J Periodontol. 2009;80(3):429-35. https://doi.org/10.1902/jop.2009.080350

28. Field EA, Longman LP, Bucknall R, Kaye SB, Higham SM, Edgar WM. The establishment of a xerostomia clinic: a prospective study. Br J Oral Maxillofac Surg. 1997;35(2):96-103. https://doi.org/10.1016/S0266-4356(97)90683-5

29. Torres SR, Peixoto CB, Caldas DM, Silva EB, Akiti T, Nucci $M$ et al. Relationship between salivary flow rates and Candida counts in subjects with xerostomia. Oral Surg Oral Med Oral Pathol Oral Radiol Endod. 2002;93(2):149-54. https://doi.org/10.1067/moe.2002.119738

30. Affoo RH, Foley N, Garrick R, Siqueira WL, Martin RE. Meta-analysis of salivary flow rates in young and older adults. J Am Geriatr Soc. 2015;63(10):2142-51. https://doi.org/10.1111/igs.13652

31. Rad M, Kakoie S, Niliye Brojeni F, Pourdamghan N. Effect of long-term smoking on whole-mouth salivary flow rate and oral health. J Dent Res Dent Clin Dent Prospects. 2010;4(4):110-4. https://doi.org/10.5681/joddd.2010.028

32. Närhi TO, Meurman JH, Ainamo A. Xerostomia and hyposalivation: causes, consequences and treatment in the elderly. Drugs Aging. 1999;15(2):103-16. https://doi.org/10.2165/00002512-199915020-00004

33. Longman LP, Higham SM, Rai K, Edgar WM, Field EA. Salivary gland hypofunction in elderly patients attending a xerostomia clinic. Gerodontology. 1995;12(2):67-72. https://doi.org/10.1111/j.1741-2358.1995.tb00133.x

34. Navazesh M1. Methods for collecting saliva. Ann N Y Acad Sci. 1993;20;694(694):72-7. https://doi.org/10.1111/j.1749-6632.1993.tb18343.x

35. Chambers MS, Posner M, Jones CU, Biel MA, Hodge KM, Vitti R et al. Cevimeline for the treatment of postirradiation xerostomia in patients with head and neck cancer. Int J Radiat Oncol Biol Phys. 2007;15;68(4):1102-9. https://doi.org/10.1016/i.ijrobp.2007.01.019

36. Leone CW, Oppenheim FG. Physical and chemical aspects of saliva as indicators of risk for dental caries in humans. J Dent Educ. 2001;65(10):1054-62.

37. Fejerskov $O$, Nyvad B, Kidd E, editors. Dental caries: the disease and its clinical management: caries control for individual patient. 3rd ed. Oxford: Blackwell Munksgaad; 2003. 